\title{
Functional significance of rising-intonation declaratives in settings with special discursive norms
}

\author{
Michael A. Shepherd \\ University of Southern California \\ mshepher@usc.edu
}

\section{Introduction}

This paper presents results of an ongoing study of variation in the intonation of students' responses to teachers' questions. We might expect such responses to be spoken with falling intonation, as this is the default for declarative utterances in English (Wells 2006), but most of the responses analyzed were in fact spoken with rising intonation. Following some background on teachers' use of questions in classroom interactions, and some information on data collection and analysis, I address the following three questions: Which students respond to teachers' questions using rising intonation? Under what circumstances? For what purposes?

\section{Background}

Questions perform different functions in classroom interactions than in casual conversations. In conversations, questions often seek information that the questioner lacks, as in the exchange in (1).

(1) A: What time is it?

B: Two o'clock.

A: Thanks.

In this exchange, participant A lacks certain information and requests it from participant B. Participant B responds by providing the requested information, and A expresses gratitude.

Teachers, by contrast, tend to ask questions for which they already have specific responses in mind (Mehan 1979). Consider the interaction in (2).

(2) Teacher: What time is it?

Student: Two o'clock.

Teacher: Good.

Although the first two utterances in this exchange are identical in form to their counterparts in (1), the first turn is not a request for information that the teacher lacks, as is made clear by the teacher's evaluative, rather than appreciative, final turn.

\section{Data and Method}

The 149 responses studied were spoken by 40 White and Hispanic students in the course of eight reading and math lessons (a total of approximately 4.5 hours' worth of classroom interaction) that I video-recorded in December 2008 in three third-grade classrooms (ages 8-9). The three teachers were White females with 11,13 , and 25 years' teaching experience, and $42 \%$ of the students were receiving free or reduced-price meals (making the school roughly lowermiddle class). For each of the responses, I noted the speaker's gender and ethnicity, and I coded the intonation as falling, level, or rising. I also noted whether the teacher's post-response feedback indicated acceptance or rejection of the student's answer. 


\section{Results and Discussion}

Of the 149 responses analyzed, $32.2 \%(n=48)$ were spoken with falling intonation, $14.1 \%(n=21)$ with level intonation, and 53.7\% $(n=80)$ with rising intonation. Beginning with the first research question - Which students respond to teachers' questions using rising intonation? - a regression analysis shows that student ethnicity is not correlated with response intonation $(t(145)=.65, p=.514)$, meaning that White students are no more or less likely to respond to questions using rising intonation than their Hispanic classmates. The analysis also reveals that girls respond to questions using rising intonation only marginally more often than boys do $(\beta=.15, t(145)=1.75, p=.083)$.

As for the second question-Under what circumstances do students respond using rising intonation? - the only significant predictor of intonation is response accuracy, with incorrect responses (identified based on the teachers' subsequent rejection) being spoken with rising intonation significantly more often than correct ones $(\beta=.31, t(145)=3.96, p<.001)$. In other words, students respond using rising intonation when they suspect a response may be incorrect.

Before proceeding to the final question and considering the purposes for which students' mark suspected incorrect responses with rising intonation, an alternative hypothesis must be addressed. Simply put, what if some students routinely use falling intonation (and these students tend to give right answers), while other students routinely use rising intonation (and these students tend give wrong answers)? If that were the case, it would account for the relationship between response intonation and response accuracy without the need for students' to be actively varying their intonation.

Of the 40 students in the data, 33 responded to at least two questions (and, thus, could exhibit within-speaker variation if they vary their intonation). Of these 33 students, $84.8 \%$ ( $n=$ 28 ) did, in fact, vary their intonation across responses. This suggests that intonation is not simply a characteristic of particular students, but rather something that they actively manipulate.

The fact that students vary their intonation from one response to another, using rising intonation when they anticipate that a particular response will be rejected, suggests a pragmatic face-saving strategy (cf. Goffman 1982, Domenici \& Littlejohn 2006). On a basic level, rising intonation serves as a marker of idea positioning (Eckert \& McConnell-Ginet 2003), lessening students' commitment to responses that they suspect are incorrect. This helps them save face insofar as giving an incorrect response is considerably less face-threatening if one never claimed to have the correct response in the first place.

Taking this a step further, a student's response is simultaneously the second part of a "teacher question-student response" adjacency pair as well as the first part of a "student response-teacher evaluation” pair (Mehan 1979), as illustrated in (3).

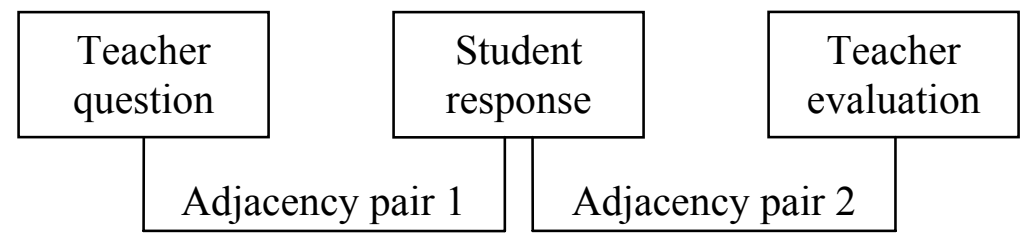


Consequently, presenting a response using rising intonation serves to deemphasize the fact that it is the answer to a question and to emphasize that it is presented for teacher evaluation. Thus, while being evaluated (particularly negatively) is potentially face-threatening, this threat can be mitigated by having solicited the evaluation from the teacher.

\section{Conclusions}

The results of the present study show that students, regardless of ethnicity and gender, vary their intonation from one response to another, using rising intonation when they anticipate that an answer will be rejected. This suggests a face-saving strategy, where rising intonation serves as a marker of idea positioning (Eckert \& McConnell-Ginet 2003), lessening students' commitment to responses that they suspect are incorrect. Moreover, since a student's response is simultaneously the second part of a "teacher question-student response" adjacency pair as well as the first part of a "student response-teacher evaluation" pair (Mehan 1979), rising intonation serves to deemphasize the fact that a response is the answer to a question and to emphasize that it is presented for teacher evaluation. Thus, students seek to mitigate the face-threat associated with negative evaluation by presenting uncertain responses as soliciting teacher evaluation.

\section{References}

Domenici, Kathy \& Stephen W. Littlejohn. 2006. Facework: Bridging theory and practice. Thousand Oaks, CA: Sage.

Eckert, Penelope \& Sally McConnell-Ginet. 2003. Language and gender. Cambridge, UK: Cambridge University Press.

Goffman, Erving. 1982. Interaction ritual: Essays on face-to-face behavior. New York, NY: Pantheon.

Mehan, Hugh. 1979. Learning lessons: Social organization in the classroom. Cambridge, MA: Harvard University Press.

Wells, John C. 2006. English intonation: An introduction. New York, NY: Cambridge University Press. 